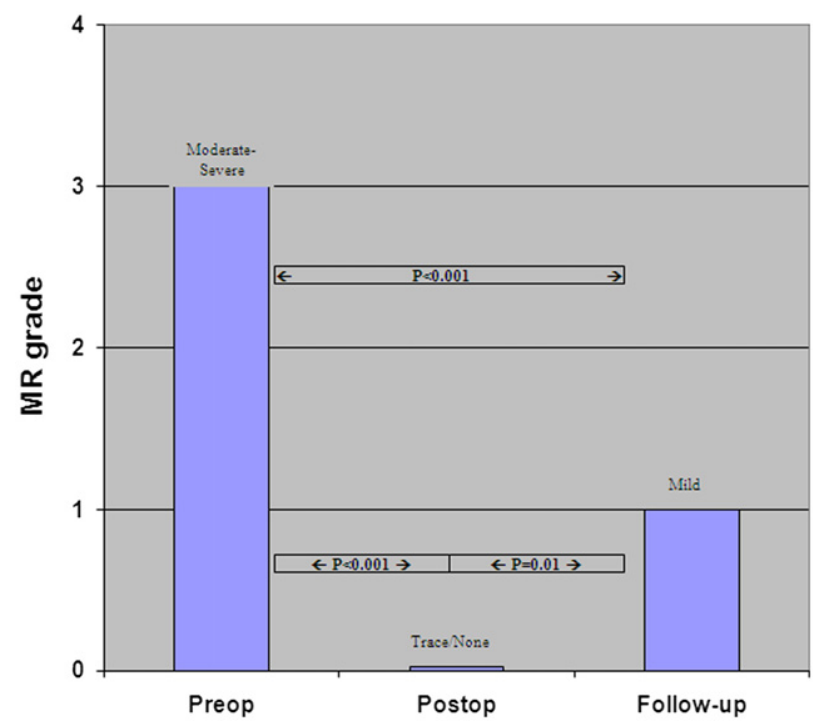

FIGURE 1. Preoperative (Preop), postoperative (Postop), and follow-up mitral valve regurgitation $(M R)$ grade.

There was $1(4 \%)$ operative mortality on postoperative day 23 , resulting from complications from acute renal failure. The median aortic crossclamp time was 101 minutes (IQR, 86-116 minutes) and the median cardiopulmonary bypass time was 127 minutes (IQR, 109-149 minutes). The median preoperative versus postoperative MR grade was 3 (IQR, 3-4) versus 0 (IQR, $0-1$ ), $P<.001$ (Table 2).

The median time to follow-up echocardiogram was 13 days (IQR, 5-93), with 5 patients having no follow-up echocardiography. The mean transmitral gradient was $4.1 \pm 2.7 \mathrm{~mm} \mathrm{Hg}$. Median preoperative versus follow-up MR grade was 3 (IQR, 3-4) versus 1 (IQR, 0-2), $P<.001$. Median postoperative versus follow-up MR grade was 0 (IQR, 0-1) versus 1 (IQR, 0-2) $P=.01$ (Table 2; Figure 1).

\section{DISCUSSION}

Our data demonstrate that in patients undergoing minimally invasive AVR with at least moderate MR originating near the A2-P2 portion of the mitral valve, a transaortic edge-to-edge mitral valve repair is a safe and effective alternative to conventional double valve surgery. The procedure adds approximately 10 minutes to the aortic crossclamp time of an AVR. The patients that did not have this procedure were those with severe mitral annulus and leaflet calcification, which we consider to be contraindications to this procedure.

\section{References}

1. Kavarana MN, Barbone A, Edwards NM, Levinsson MM, Oz MC. Transaortic repair of mitral regurgitation. Heart Surg Forum. 2000;3:24-8.

2. Kim SW, Park PW. Transaortic mitral commissuroplasty with a Bentall procedure or aortic valve replacement. Korean J Thorac Cardiovasc Surg. 2007;40: 727-32.

3. Santana O, Panchamukhi KB, Grana R, Traad EA. Transaortic repair of the mitral valve in patients undergoing aortic valve replacement. Heart Surg Forum. 2009; $12: 1-4$.

4. Santana O, Lamelas J. Minimally invasive transaortic repair of the mitral valve Heart Surg Forum. 2011;14:E232-6.

5. Santana O, Lamelas J. Minimally invasive transaortic mitral valve repair during aortic valve replacement. Texas Heart J. 2011;38:298-300.

\title{
Partial transplant cardiectomy mitral exposure
}

\author{
Scott D. Lick, MD, Daniel L. Beckles, MD, PhD, and Vincent R. Conti, MD, Galveston, Tex
}

\begin{abstract}
Although a traditional groove of Sondergaard left atriotomy incision gives adequate mitral valve exposure in most instances, for difficult cases alternative approaches can be helpful. Radical approaches to the difficult mitral valve through sternotomy have included azygos division with

\footnotetext{
From the Department of Surgery, University of Texas Medical Branch, Galveston, Tex.

Disclosures: Authors have nothing to disclose with regard to commercial support.

Received for publication Nov 9, 2012; revisions received Dec 13, 2012; accepted for publication Jan 14, 2013; available ahead of print Feb 11, 2013.

Address for reprints: Scott D. Lick, MD, Department of Surgery, University of Texas

Medical Branch, 301 University Blvd, Galveston, TX 77555-0528 (E-mail: slick@ utmb.edu).

J Thorac Cardiovasc Surg 2013;145:1413-4

$0022-5223 / \$ 36.00$

Copyright (C) 2013 by The American Association for Thoracic Surgery

http://dx.doi.org/10.1016/j.jtcvs.2013.01.033
}

superior vena cava mobilization, ${ }^{1}$ superior vena cava transection, $^{2}$ and the superior transseptal approach. ${ }^{3,4}$ Drawbacks to these approaches include loss of azygos venous drainage, possible stenosis of the reconstructed superior vena cava, and possible sinoatrial node dysfunction. $^{3,5}$ In a difficult mitral case, however, possible transient sinus node dysfunction is a small trade-off in light of the generally excellent exposure the transseptal exposure provides, and so this approach has become relatively common. Occasionally, though, even the transseptal incision does not provide good mitral exposure through a sternotomy.

The partial cardiectomy approach begins with a standard superior transseptal incision, with bicaval cannulation and caval snares. After aortic crossclamping, the right atrium 


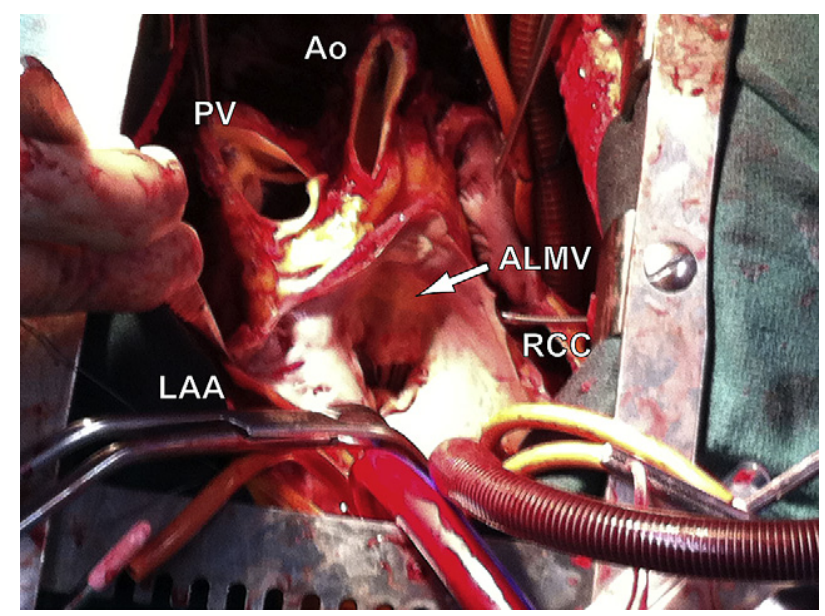

FIGURE 1. Anesthesiologist's view. $A L M V$, Anterior leaflet of mitral valve; $A o$, aortic root; $L A A$, left atrial appendage; $P V$, pulmonary valve; $R C C$, retrograde cardioplegia cannula.

is opened on the appendage, the dome of the left atrium is identified, and a transatrial septal incision through the fossa ovalis is carried onto the dome, leaving enough atrium toward the aorta for easy reconstruction, as depicted by Smith $^{3}$ and Guiraudon and colleagues. ${ }^{4}$ The right atrial and atrial septal incisions are carried down toward but short of the inferior vena cava and coronary sinus, respectively. If this transseptal exposure is insufficient, the aorta is transected just above the sinotubular junction, the atrial dome incision is extended, and the heart is retracted anteriorly. If mitral exposure is still inadequate, the pulmonary artery is also transected just above the sinotubular junction, and the dome atriotomy is continued leftward in front of the left pulmonary veins and behind the left atrial appendage. The heart is rolled toward the feet, exposing all 4 valves (Figure 1). After the mitral operation, closure proceeds similarly to a heart transplant: the left atrium, followed by the medial right atrium (the free wall of the right atrium can be left unsewn until after crossclamp release), the pulmonary artery (with patch repair of the right pulmonary artery if thinned), and finally the aorta.

We have found this exposure particularly useful for mitral access in the presence of a rigid prosthetic aortic valve, which otherwise bulges in front of the mitral valve and obscures access through traditional incisions, including the right thoracotomy approach. With this approach,
TABLE 1. Patients undergoing mitral operations through the partial transplant cardiectomy incision

\begin{tabular}{lllc}
\hline Case & Previous operation & \multicolumn{1}{c}{ Index operation } & Outcome \\
\hline 1 & $\begin{array}{l}\text { Valve-sparing root } \\
\text { replacement plus }\end{array}$ & $\begin{array}{c}\text { Tissue MVR, tissue } \\
\text { AVR, tricuspid DeVega, }\end{array}$ & Alive and well \\
& mitral repair & CABG $\times 1$ (with division \\
& \multicolumn{3}{c}{ and reconstruction of } \\
& \multicolumn{4}{c}{ pulmonary artery) } \\
2 & None & AVR, MVR & Alive and well \\
3 & AVR & MVR & Alive and well \\
4 & None & AVR, MVR & Alive and well \\
5 & AVR & MVR & Alive and well \\
6 & None & MVR, tricuspid DeVega & Alive and well \\
\hline$A V R$, Aortic valve replacement; $C A B G$, coronary artery bypass grafting; $M V R$, mitral \\
valve replacement.
\end{tabular}

the aortic root with the prosthetic aortic valve is elevated like a retractor, helping rather than hurting exposure.

The incision and exposure can easily be practiced with each heart transplant recipient cardiectomy. We consider it the ultimate sternotomy approach to the difficult mitral valve (frozen heart), often related to such factors as previous aortic valve replacement, irradiation, small left atrium, and dense adhesions. Although it involves extra suturing, these same factors (except for the small atrium) provide thick, hemostatic tissue to help hemostasis at reconstruction. We have used the 3-valve exposure in 5 cases, and full 4-valve (pulmonary transection with right pulmonary arterial patch for thinned tissue) in 1 particularly difficult case (Table 1). Although it appears radical, it is arguably conservative. It is merely a stepwise progression beyond the standard superior transseptal incision. If the conventional incision provides sufficient exposure, it is not needed. It also provides excellent exposure for multivalve procedures.

\section{References}

1. Zacharias A. Alternative method to improve exposure for difficult mitral valve procedures. Ann Thorac Surg. 1986;42:336-7.

2. Selle JG. Temporary division of the superior vena cava for exceptional mitral valve exposure. J Thorac Cardiovasc Surg. 1984;88:302-4.

3. Smith CR. Septal-superior exposure of the mitral valve. The transplant approach. $J$ Thorac Cardiovasc Surg. 1992;103:623-8.

4. Guiraudon GM, Ofiesh JG, Kaushik R. Extended vertical transatrial septal approach to the mitral valve. Ann Thorac Surg. 1991;52:1058-60; discussion 1060-2.

5. Lukac P, Hjortdal VE, Pedersen AK, Mortensen PT, Jensen HK, Hansen PS. Superior transseptal approach to mitral valve is associated with a higher need for pacemaker implantation than the left atrial approach. Ann Thorac Surg. 2007;83:77-82. 